Pesquisa em Foco ISSN (2176-0136)

http://ppg.revistas.uema.br/index.php/PESQUISA EM FOCO

São Luís, v. 22, n. 2, Jul./Dez. 2017

\title{
A EDUCAÇÃO DE JOVENS E ADULTOS: DE PAULO FREIRE ÀS METAS DO PNE
}

\author{
Marcos Teles Nunes ${ }^{1}$, Ana Paula Domingos Baladeli ${ }^{2}$
}

\section{RESUMO}

A Educação de Jovens e Adultos - EJA consiste em expandir o ensino fundamental e médio para pessoas que não tiveram oportunidade de estudo na idade correta, respeitando as singularidades da educação de alunos adultos. No contexto das políticas públicas, a modalidade EJA desperta diferentes reflexões visto que, historicamente, tem encontrado dificuldades para consolidar-se em termos de reconhecimento social. Esta pesquisa bibliográfica tem o objetivo de analisar a modalidade EJA no contexto das pesquisas sobre do PNE. Os dados indicam que a EJA tem sofrido com o descaso das políticas públicas, estas que se apresentam pouco efetivas na inserção e permanência do aluno jovem e adulto na escola. Além disso, destacamos o desafio de compreensão da função social da modalidade como oportunidade formativa que demanda professores qualificados e conscientes das especificidades da Alfabetização de Jovens e Adultos.

Palavras-chave: Educação de Jovens e Adultos; Plano Nacional de Educação; Paulo Freire.

\section{YOUTH AND ADULT EDUCATION: FROM PAULO FREIRE TO PNE'S GOALS}

\footnotetext{
1 Graduando em Pedagogia pela Universidade Estadual do Oeste do Paraná. Brasil. E-mail: marcostelesnunes@hotmail.com

${ }^{2}$ Doutora em Letras (Linguagem e Sociedade) pela Universidade Estadual do Oeste do Paraná. Brasil. Email: annapdomingos@yahoo.com.br
} 


\section{ABSTRACT}

Youth and Adult Education (EJA) consists of expanding primary and secondary education to people who have not had the opportunity to study at the proper age, respecting the singularities of adult education. In the context of public policies, the EJA modality arouses different reflections since, historically, it has found difficulties to consolidate itself in terms of social recognition. This bibliographic research has the aim to analise the EJA modality within PNE researches. The data indicate that the EJA has suffered from the neglect of public policies, which are ineffective in the insertion and permanence of the young and adult students in school. In addition, we highlight the challenge of understanding the social function of that modality as a formative opportunity that demands qualified teachers and aware of the specificities of Youth and Adult Literacy.

Keywods: Youth and adult education; National Education Plan; Paulo Freire.

\section{INTRODUÇÃO}

Conhecida como modalidade de ensino que abrange a todos que não tiveram a oportunidade de estudar ou abandonaram os estudos na idade correta, a Educação de Jovens e Adultos (EJA) é amparada pela Lei de Diretrizes e Bases da Educação Nacional - LDBEN Lei n. 9.394, de 20 de dezembro de 1996, que prevê o acesso de todos à educação escolar.

A modalidade EJA no Brasil tem uma longa história, envolta na multiplicidade de debates acerca das principais reivindicações para a superação do analfabetismo, tema recorrente nas políticas nacionais de educação. Além de representar um direito, a educação de jovens e adultos oportuniza o desenvolvimento pessoal e profissional por meio da universalização do conhecimento científico (PARANÁ, 2010). Observamos nas publicações sobre a EJA o destaque às ações educativas no processo pedagógico e a carência de maior preocupação com o perfil do professor apto a atuar na EJA. 
Pesquisa em Foco ISSN (2176-0136)

http://ppg.revistas.uema.br/index.php/PESQUISA EM FOCO

São Luís, v. 22, n. 2, Jul./Dez. 2017

A EJA, no Brasil, carece de um currículo específico de ensino que tanto relacione os conhecimentos sistematizados do educador, quanto considere os conhecimentos de mundo e o contexto sociocultural dos alunos. O discurso acerca da EJA presente nas políticas públicas confronta-se com os currículos e as diretrizes estabelecidos para a modalidade, visto que, ao mesmo tempo em que propõem a valorização da EJA e sua dimensão humanizadora, não garantem o cumprimento de sua oferta com eficiência e nem apresentam os fundamentos para a formação do professor que atuará na modalidade (NOGUEIRA e MIRANDA, 2001; BEISIEGEL, 2010; PELETTI, 2016).

Historicamente, o sistema escolar no Brasil passou por avanços que não podem ser desconsiderados, sendo um deles a inclusão da EJA como modalidade de ensino a ser ofertada a todos que não tiveram a oportunidade de estudar na idade correta. Desde a Constituição Imperial do Brasil de 1824, registrou-se pela primeira vez instrução primária e gratuita a todos os cidadãos. Em 1932, um grupo de educadores apresentou um documento conhecido como Manifesto dos Pioneiros da Educação Nova, o qual propunha tanto uma renovação educacional, quanto maior responsabilidade do Estado na oferta de uma educação geral e igualitária (ROMANELLI, 1978). O documento também colaborou com a inclusão de um artigo específico em que se estabelecia ser da competência da união fixar o Plano Nacional de Educação PNE (BRASIL, 2001).

Segundo Romanelli (1978), mesmo com o Manifesto dos Pioneiros da Educação, o ensino continuou passando por contradições, a crescente procura do público adulto pela escola, levou a ser instalado o ensino supletivos em 1947, colaborando assim com o aumento do índice de alfabetismo, porém, não ocorreu mudança significativa na estrutura escolar do país, que levasse a melhorar a qualidade do ensino.

No período do governo de Getúlio Vargas a educação ascendeu como setor estratégico no projeto de nação que, se pretendia alcançar por meio do desenvolvimento do país. Para Cunha (1991), a educação profissionalizante 
apresentou-se como uma alternativa do governo para empreender o crescimento industrial almejado, acreditando que, por meio da formação manufatureira do trabalhador a economia nacional seria beneficiada. Foi com a Reforma Capanema e a reestruturação do ensino industrial com o Serviço Nacional de Aprendizagem Industrial (Senai) que a proposta de qualificação de mão de obra tornou-se central nas políticas públicas da época. Diante disso, houve a necessidade de regulamentar e estabelecer diretrizes para o sistema educacional brasileiro, sendo lançado então ao Congresso Nacional em 1948 o projeto de Lei de Diretrizes e Bases da Educação Nacional n.4.024/61 (LDBEN). Envolto em discussões no Congresso, o documento só foi aprovado 13 anos mais tarde. Assim, em 1961 estabeleceu a obrigatoriedade do ensino primário com idade mínima e, a criação de classes especiais para o atendimento de alunos fora da idade ou supletivos (SAVIANI, 1988).

A partir de 1967, o presidente do regime militar Marechal Costa e Silva, preocupado com os altos números de analfabetos no Brasil, enviou ao Congresso 0 Plano de Alfabetização Funcional e Educação Continuada de Adultos, ao qual ficaria submetido a execução da Fundação MOBRAL - Movimento Brasileiro de Alfabetização (BRASIL, 1973). Em dezembro do mesmo ano seria aprovada a Lei n. 5.379/67, iniciando assim os trabalhos na Fundação Mobral com foco na erradicação do analfabetismo (CORRÊA, 1979).

Esta pesquisa bibliográfica se justifica pela necessidade de refletir sobre a modalidade da Educação de Jovens e Adultos na atualidade com foco nas metas estabelecidas para a mesma conforme o Plano Nacional de Educação - PNE. Feita esta breve contextualização histórica acerca do percurso da EJA no país, apresentamos na sequência nossa pesquisa bibliográfica que teve o objetivo de analisar a modalidade EJA no contexto das pesquisas sobre o PNE. Nossa fundamentação teórica foi composta pelos documentos específicos da modalidade, obras de Paulo Freire e também pesquisas científicas que abordam a EJA e as metas do Plano Nacional de Educação - PNE.

Diante disso, organizamos o artigo em três seções. Na primeira - Paulo Freire $e$ a Educação de Jovens e Adultos, apresentamos os pressupostos que nortearam a 
Pesquisa em Foco ISSN (2176-0136)

http://ppg.revistas.uema.br/index.php/PESQUISA EM FOCO

São Luís, v. 22, n. 2, Jul./Dez. 2017

concepção de educação defendida por Paulo Freire. Em - Pesquisas sobre a modalidade EJA, nossa segunda seção, apresentamos alguns resultados de dissertações que versaram sobre a EJA. Na terceira seção - O PNE e o planejamento da educação brasileira, sistematizamos os conteúdos do plano, suas metas e alguns indicadores. Nas considerações finais - problematizamos o investimento e falta de priorização da EJA no contexto da formação de professores.

\section{PAULO FREIRE E A EDUCAÇÃO DE JOVENS E ADULTOS}

O debate acerca das características e da função social da EJA no país, destacouse mediante as publicações de Paulo Freire. Argumentando a necessidade de a educação de jovens e adultos seguir uma perspectiva transformadora, em que a ação pedagógica estivesse aliada à formação do cidadão, Freire $(2003 ; 2011)$ defendia a educação como uma via de conscientização para a transformação. As contribuições de Freire são observadas, sobretudo na alfabetização, esta que deveria resultar de uma intervenção pedagógica, intencional, política e comprometida com o conhecimento prévio do educando.

Assim, o papel do educador não deveria ser o de desconsiderar os conhecimentos prévios do educando, pelo contrário, deveria ter sua prática pedagógica organizada no sentido de reconhecer primeiro o contexto do qual o educando é originário. Dessa maneira, o conhecimento não é compreendido como um conjunto de dados estanques e acomodados, visto que educadores e educandos participariam dialeticamente do processo de conscientização via educação (FREIRE, 2003).

Na obra A importância do ato de ler: em três artigos que se completam Freire (2003) criticava a educação reprodutora, em que o professor e o aluno desempenhavam papéis dicotômicos o que denominava de educação bancária, na qual o professor depositava o conhecimento na cabeça do educando. Segundo Freire (2011) no processo de alfabetização, educador e educando compartilhariam de 
conhecimentos e cultura, assim, no movimento dialético, ambos desempenhariam papel relevante nos processos de ensino e aprendizagem. Para Freire,

\begin{abstract}
Como um ato de conhecimento, o processo de alfabetização implica na existência de dois contextos dialeticamente relacionados. Um é o contexto do autêntico diálogo entre educadores e educandos, enquanto sujeitos de conhecimento. É o contexto teórico. O outro é o contexto concreto, em que os fatos se dão a realidade social em que se encontram os alfabetizados (FREIRE, 2011, p. 40).
\end{abstract}

O método de alfabetização defendido por Paulo Freire buscava o desenvolvimento do educando, a formação da consciência crítica e o caráter democrático da educação, portanto, propunha o ensino a partir de palavras geradoras em vez do uso de cartilhas e livros padronizados (FREIRE, 2003; BEISIEGEL, 2010; KOSSMANN e BALADELI, 2012). Como parte integrante da alfabetização, propunha utilizar em seu método conceitos de cultura, por meio de figura ou imagens simples, no qual os educandos eram questionados sobre os significados das imagens utilizadas. A literatura sobre Freire indica que a educação além de ser considerada como ato político e não neutro representaria uma forma de transformar a realidade. Por essa razão, acreditava que a escola representava um espaço privilegiado de discussão e diálogo entre educandos e educadores em busca da libertação e da conscientização.

Por meio de pesquisa bibliográfica Kossmann e Baladeli (2012), discutiram os pressupostos da educação progressista considerando as relações de poder, as circunstâncias sociais, políticas e ideológicas subjacentes ao ato de ensinar. Além de adotar uma educação prezando pelas diferentes culturas, também defendem uma educação crítica e responsável em que os conteúdos sejam problematizados e o diálogo entre educador e educando sejam priorizados na prática pedagógica.

A questão central que emerge dos estudos da obra de Freire é a importância de problematizar a ação educativa, superando a lógica da educação bancária de transmissão de conhecimento. Devido à sua contribuição para o cenário educacional brasileiro em 13 de abril de 2012 por meio da Lei n. 12.612, o educador Paulo Freire é reconhecido como Patrono da Educação Brasileira, sendo ainda reconhecido por seu 
Pesquisa em Foco ISSN (2176-0136)

http://ppg.revistas.uema.br/index.php/PESQUISA EM FOCO

São Luís, v. 22, n. 2, Jul./Dez. 2017

pioneirismo na alfabetização de jovens e adultos (BRASIL, 2012). Porém, uma aluna defensora da escola sem partido, enviou uma Ideia Legislativa3, onde atualmente tramita no Senado Federal a Sugestão no 47, de 2017, que busca a revogação da lei que institui Paulo Freire como patrono da educação brasileira.

A presente pesquisa caracteriza-se como básica e bibliográfica, pois segundo Marconi e Lakatos (2003), a pesquisa bibliográfica é uma investigação feita em diversos trabalhos publicados, como livros ou revistas, que apresentam informações pertinentes que ajudarão no desenvolvimento do estudo. Além disso, um dos principais benefícios da pesquisa bibliográfica é o contato que o pesquisador terá com as diversas conclusões sobre seu tema de pesquisa. Deste modo, embasado na importância da pesquisa bibliográfica apresentamos algumas dissertações e teses relacionadas à Educação de Jovens e Adultos e o PNE.

\section{PESQUISAS SOBRE A MODALIDADE EJA}

Segundo as Diretrizes Curriculares a Educação de Jovens e Adultos, dentre as funções da modalidade estão "[...] compromisso com a formação humana e com o acesso à cultura geral, de modo que os educandos aprimorem sua consciência crítica, e adotem atitudes éticas e compromisso político, para o desenvolvimento da sua autonomia intelectual" (PARANÁ, 2006, p. 27). O referido documento ainda preconiza que os conteúdos da EJA sejam organizados e adaptados a partir da realidade do educando, razão pela qual o ensino nesta modalidade deve caracterizar-se como flexível e contextualizado.

Em levantamento de pesquisas sobre a EJA destacamos a dissertação realizada por Peletti (2016), que objetivou compreender as demandas dos alunos da EJA de uma instituição de ensino do interior do Paraná. Os dados foram coletados mediante

3 Ideia Legislativa $\mathrm{n}^{\circ}$. 90.310 recebeu mais de 20.000 apoios e foi transformada na Sugestão n. 47 de 2017, que está em consulta pública e tramitação na CDH - Comissão de Direitos Humanos e Legislação Participativa. Disponível em:<http://www.senado.gov.br/sigadweb/v.aspx> acesso em 31 out. 2017. 
entrevistas com professores, funcionários e ex-alunos e concluiu que a escola representa uma forma de controle social, tendo em vista que ao longo da história sua função está sempre reproduzindo uma ideologia presente na sociedade. $\mathrm{O}$ autor concluiu que há uma contradição entre o discurso das políticas públicas e a realidade das instituições que oferecem essa modalidade de ensino. Para Peletti (2016) a modalidade continua enfrentando dificuldades no campo das políticas públicas e também no sentido de instituir uma compreensão crítica do papel da EJA na sociedade. Já no que diz respeito à formação docente, o pesquisador enfatizou a necessidade de os professores serem capacitados para atender as necessidades das salas de aula de EJA, concluindo que as políticas públicas pouco refletem na eficiência dos programas de formação ofertados.

A dissertação de Ferrari (2015) teve o objetivo de contribuir com uma metodologia diferenciada na EJA e, para tanto, analisou as histórias de vida de oito alunos de uma instituição de EJA. Por meio de entrevista e da produção de histórias de vida a pesquisadora concluiu que, atualmente, não podemos afirmar que exista um perfil específico de alunos da EJA, pois as práticas sociais variam consideravelmente, tornando assim, a sala de aula um espaço heterogêneo e plural. Além disso, Ferrari (2015) constatou que os alunos da EJA tendem a valorizar apenas a aprendizagem da leitura, o que segundo a pesquisadora, acaba fazendo com que haja uma visão limitada dos conhecimentos que a escola pode oferecer. Destacou ainda que a escola precisa adotar pedagogias adequadas ao público jovem e adulto, adequando assim os conteúdos escolares às curiosidades e repertórios socioculturais dos alunos.

A dissertação de Veloso (2014) que teve o propósito de analisar como ocorrem as práticas pedagógicas na EJA verificou o cumprimento dos objetivos definidos na legislação e nos documentos oficiais da modalidade. Para tanto, investigou as ocorrências na sala de aula e no trabalho diário envolvendo as práticas pedagógicas conduzidas pelo professor em uma instituição no Estado do Pará. A pesquisa qualitativa incluiu a metodologia de análise documental, além de coleta de dados com a observação participante e entrevista com 05 professores e 05 alunos da EJA. A autora constatou que, mesmo previsto no Conselho Nacional de Educação, a formação 
Pesquisa em Foco ISSN (2176-0136)

http://ppg.revistas.uema.br/index.php/PESQUISA EM FOCO

São Luís, v. 22, n. 2, Jul./Dez. 2017

específica do professor para à EJA, seus dados indicaram o não cumprimento da legislação. Em sua observação, verificou que as estruturas físicas das instituições que ofertam EJA não condizem com o previsto no regimento das escolas estaduais do Pará, não oferecendo condições de permanência, gerando a insatisfação no aluno, que considera a escola apenas como uma via para obtenção do diploma. No que se refere aos assuntos e temas dos currículos, a autora percebeu a incompreensão por parte dos professores acerca do papel da escola e mesmo, quanto ao seu próprio papel, refletindo estes nos encaminhamentos metodológicos adotados em sala.

A dissertação de Silva (2014) investigou as políticas educacionais da EJA, focalizando o educador por meio de uma pesquisa historiográfica e documental. Para a pesquisadora, na atualidade não se discute a obrigatoriedade de ensino, mas sim, as condições de permanência e qualidade de ensino oferecido. Além do mais, quando se trata de educação, desde a publicação LDBEN, observamos a morosidade na sistematização de um sistema educacional nacional.

O Plano Nacional de Educação - PNE, por exemplo, levou quatro anos para ter seu projeto aprovado na Câmara dos Deputados e mesmo assim, a questão de formação de professores ainda não foi contemplada de forma objetiva na versão final do documento. Para Silva (2014) o problema reside no fato de a formação docente para a EJA não ser incluída de forma sistemática nos cursos de licenciaturas, deixando a critério dos cursos a inclusão da modalidade em suas ementas. A autora destacou que nas matrizes curriculares dos cursos de licenciatura, a modalidade não está contemplada de forma a subsidiar a atuação de futuros professores. Além disso, argumenta que mesmo que existam disciplinas dedicadas ao estudo da EJA, não há uma carga horária específica para a realização do estágio curricular supervisionado nesta modalidade. Na análise de Silva (2014), o Brasil não vem cumprindo com os acordos internacionais no que se refere aos investimentos específicos e que também não tem se preocupado com a formação docente voltada para a EJA, o que faz com que a modalidade permaneça em segundo plano se comparada ao ensino regular. 
Em seu estudo Di Pierro (2010), discutiu o desajuste observado na real importância dada nas políticas públicas relacionadas a EJA com as ações promulgadas no PNE 2001-2010. Segundo a autora, na proposta encaminhada para o Congresso Nacional não apresentavam mudanças significativas para EJA, apenas buscavam estratégias para elevar a alfabetização dos alunos, descentralizando a obrigação do custeio com a EJA. A autora concluiu que se faz necessário tanto rever a concepção de alfabetização de jovens e adultos, como sinônimo de formação rápida e compensatória, quanto estabelecer metas e estratégias que considerem as discrepâncias socioeconômicas que caracterizam o público atendido na modalidade.

Com o objetivo de analisar as conquistas e perdas no processo de construção do PNE, Bezerra e Machado (2016) destacaram a importância de investir na criação de cursos de licenciatura específicos para a formação docente para a EJA. Segundo as autoras, as ações de programas como Brasil Alfabetizado (PBA) perpetuam a lógica de transferência da responsabilidade do Estado para o voluntariado, na qual o educador é considerado como apto para alfabetizar jovens e adultos apenas com ensino médio ou equivalente. Quanto à formação de docentes, as autoras lembram que a Meta - 15 do PNE prevê a formação dos profissionais da educação de modo geral, porém destaca que estas, poderão não ser atingidas se não for respeitado os $10 \%$ do produto interno bruto (PIB) para investimento em educação.

Conforme destacamos nas seções anteriores, a EJA historicamente tem enfrentado desafios que vão desde a compreensão do papel social da modalidade, a formação docente e até o investimento em infraestrutura e em políticas de permanência dos alunos. Nesta pesquisa, fundamentamos a caracterização da EJA na perspectiva educacional de Paulo Freire, que defendeu a necessidade de a educação de adultos incluir a educação política e conscientizadora. Para o educador, a EJA deve colaborar para que o educando assuma papel ativo no processo de problematização da realidade (FREIRE, 2003; 2007).

Na próxima seção, apresentamos os objetivos do Plano Nacional de Educação e as metas específicas para a modalidade EJA. 
Pesquisa em Foco ISSN (2176-0136)

http://ppg.revistas.uema.br/index.php/PESQUISA EM FOCO

São Luís, v. 22, n. 2, Jul./Dez. 2017

\section{O PNE E O PLANEJAMENTO DA EDUCAÇÃO BRASILEIRA}

O Plano Nacional de Educação - PNE Lei n. 13005, de 25 de junho de 2014 foi aprovado pelo Congresso Nacional e tem como objetivo estabelecer diretrizes para o sistema de educação nacional por meio da criação de metas e estratégias. A referida política pública está em consonância ao art.214 da Constituição Federal, em que se previa a necessidade de o país organizar, monitorar e aplicar um plano nacional para a sistematização de metas a serem alcançadas na educação.

O PNE é composto por 20 metas e 254 estratégias que deverão ser cumpridas no prazo máximo de 10 anos; sendo 03 metas $^{4}$ e 37 estratégias específicas para a EJA. As metas do PNE foram organizadas em grupos: o primeiro grupo apresenta metas estruturantes para a garantia do direito à educação básica com qualidade. O segundo grupo fala sobre redução das desigualdades e à valorização da diversidade, o terceiro aborda a valorização dos profissionais da educação, e o último grupo de metas referese ao ensino superior. O plano inclui estratégias para todos os níveis da educação, desde a educação infantil até o ensino superior na tentativa de "[...] aproximar ainda mais, agentes públicos e sociedade em geral dos debates e desafios relativos à melhoria da educação, tendo por eixo os processos de organização e gestão da educação, seu financiamento, avaliação e políticas de estado" (BRASIL, 2014b, p.06).

O segundo PNE foi elaborado a partir das diretrizes da Constituição Federal de 1988, na qual, em seu artigo 214, estabeleceu que o plano deveria ter duração decenal, visando a articulação em regime de colaboração entre o sistema nacional com o estadual e municipal. Para tanto, propôs a definição de diretrizes, objetivos, metas e

\footnotetext{
${ }^{4}$ Meta 9: elevar a taxa de alfabetização da população com 15 (quinze) anos ou mais para 93,5\% (noventa e três inteiros e cinco décimos por cento) até 2015 e, até o final da vigência deste PNE, erradicar o analfabetismo absoluto e reduzir em $50 \%$ (cinquenta por cento) a taxa de analfabetismo funcional. Meta 10: oferecer, no mínimo, $25 \%$ (vinte e cinco por cento) das matrículas de educação de jovens e adultos, nos ensinos fundamental e médio, na forma integrada à educação profissional. Meta 11: triplicar as matrículas da educação profissional técnica de nível médio, assegurando a qualidade da oferta e pelo menos 50\% (cinquenta por cento) da expansão no segmento público (BRASIL, 2014a, online)
} 
estratégias de implementação e manutenção do desenvolvimento do ensino em seus diversos níveis, etapas e modalidades por meio de ações integradas dos poderes públicos das diferentes esferas federativas (BRASIL, 1988).

Em janeiro de 2001, foi sancionada a Lei n. 10.172/2001 do Plano Nacional de Educação que apresentava o propósito de diagnosticar a situação do ensino nacional e estabelecer um conjunto de diretrizes e metas a serem executadas pela União, estados e municípios. Com a Emenda Constitucional n, 59, de 11 de novembro de 2009 mudou a condição do Plano Nacional de Educação (PNE), que passou de uma disposição transitória da Lei de Diretrizes e Bases da Educação Nacional (Lei n. 9.394/1996) para uma exigência constitucional com periodicidade decenal.

Em vigência desde 2014, o PNE, objetiva sensibilizar os entes federados a responsabilizarem-se pela educação ofertada nas esferas municipal e estadual, promovendo a criação de espaços formativos para o debate público acerca da qualidade da educação (BRASIL, 2014).

Em consulta ao Relatório do 1ํ Ciclo de Monitoramento do PNE: Biênio 2014$2016^{5}$, onde são monitorados cumprimento das metas por região ou estados, a meta 9 no Estado do Paraná já foi alcançada, como o objetivo da meta 9 era elevar a taxa de alfabetização da população com 15 anos ou mais para 93,5\% até 2015 , estando o Paraná conta com 95,0\%, superando então a estimativa. Porém, segundo o relatório, o Brasil conta com 91,7\% em 2014, não atingindo a meta de 93,5\% em 2015. Considerando que a meta 09 objetiva erradicar o analfabetismo absoluto, o Estado do Paraná vem descumprido com o objetivo, pois conta com uma taxa 5,8\% de analfabetos, e precisaria reduzir em pelo menos $50 \%$ a taxa de analfabetismo funcional, que atualmente está em 15,7\%, ou seja, até o final da vigência do PNE, este valor deve alcançar no mínimo 9\%. Para o Brasil, o relatório mostra, que até 2014 faltam ainda 8,4 p.p, para que seja diminuída em $50 \%$ a taxa de analfabetismo de $9,2 \%$ até 2024.

5 Disponível em:< https://goo.gl/QTEi69 > acesso em 20 set. 2017. 
Pesquisa em Foco ISSN (2176-0136)

http://ppg.revistas.uema.br/index.php/PESQUISA EM FOCO

São Luís, v. 22, n. 2, Jul./Dez. 2017

[...] um crescimento na taxa de alfabetização da população de 15 anos ou mais, que passou de $88,5 \%$, em 2004, para 91,7\%, em 2014, o que posicionou o indicador 1,8 p.p. abaixo do proposto pela meta. Essa tendência de crescimento ocorreu em todas as grandes regiões do País. É preciso ressaltar, porém, que a região Nordeste apresentou, em 2014 , uma taxa de $83,4 \%$, o que a posicionava 8,3 p.p. abaixo da taxa nacional, no mesmo período (BRASIL, 2016, p. 230).

Quanto ao cumprimento da Meta 10, que objetiva integrar a EJA à Educação Profissional. Verificamos que o Brasil conta com apenas 3\% de matriculas integrada a educação profissional, precisando de 23 p.p para atingir a meta até 2024. Já o Paraná, possui apenas $1 \%$ da conquista desta meta, necessitando de 24 p.p até o final da vigência deste PNE. A educação profissional, também relacionada a Meta 11, busca triplicar o número de matriculas da educação profissional técnica de nível médio, que em 2013 era de 1.602.946 matrículas, sendo necessário chegar a 4.808.838 matrículas até 2024, segundo dados do 1 ㅇ Biênio, em 2015 era ofertado 1.826.289 matrículas, ou seja, para triplicar a oferta será necessário criar 2.982.549 novas matrículas até 2024, usando como referência o ano de 2015. Além disso, a meta também busca expandir em 50\% estas matriculas para o segmento público, ou seja, do valor apontado em 2013 de 1.602.946 matriculas, será necessário criar 1.525 .415 matriculas o segmento público, já que está modalidade teve um aumento de 77.531 matriculas em 2015.

Conforme Portal $\mathrm{G}^{6}{ }^{6}$, com mais de um terço do tempo de vigência do PNE, suas metas podem não ser cumpridas, já que com a aprovação no Congresso Nacional para a Lei n. 13.473, de 08 de agosto de 2017, Lei de Diretrizes Orçamentárias - LDO para o próximo ano haverá alocação de recursos da educação para outras áreas. Com a redução de investimento na educação, o cumprimento das 20 metas do PNE pode ser comprometido. Em linhas gerais, para o governo, ao priorizar as metas do PNE corre-se o risco de comprometer a meta fiscal. Tal justificativa evidencia que a prioridade não

6 Disponível em:< https://goo.gl/7ZrLDc $>$ acesso em 26 set. 2017. 
tem sido a melhoria da qualidade da educação, mas o contingenciamento da crise econômica do país.

Diante da expectativa de alcançar $25 \%$ de matrículas da EJA integrada à educação profissional, para Alvarenga (2016) a proposta apresenta-se um tanto quanto audaciosa, pois lembra que historicamente, a modalidade tem sido prejudicada com a crise econômica e a transição de governos, fatores que interrompem ou atrasam a implementação de uma educação de qualidade. A autora destaca que a proposta da Emenda Constitucional - PEC 241 descumpre o atual plano e compromete o próximo, além de levar ao sucateamento da escola pública prejudicando a qualidade do ensino. Para a autora, as metas relacionadas à EJA devem ser analisadas em conjunto, pois envolvem questões políticas, econômicas e sociais, cabendo ao poder público a fiscalização e o cumprimento das metas.

No que se refere à meta 11 , o Estado do Paraná dispõe do programa de Educação Profissional Integrada à Educação de Jovens e Adultos - PROEJA, em que se verifica:

\begin{abstract}
A integração entre o Ensino Médio e Educação Profissional, para o público da EJA, possibilita o acesso à educação formal e profissional, na perspectiva de uma formação integral. Considerando-se que a escolarização, muitas vezes, é o primeiro passo para a inclusão do educando no mundo do trabalho, bem como, o acesso às demais oportunidades (PARANÁ, 2010, p. 20).
\end{abstract}

O documento em consonância com as políticas educacionais busca universalizar a educação básica aliada ao mercado de trabalho, melhorando a compreensão de mundo do aluno. Também fala da importância em oferecer educação pública e gratuita respeitando as especificidades do público.

As metas 9, 10 e 11 direcionadas à EJA enfatizam a necessidade de ampliar o número de matrículas e vincular a formação integral à profissionalização, considerando as especificidades do público que frequenta a modalidade. 
Pesquisa em Foco ISSN (2176-0136)

http://ppg.revistas.uema.br/index.php/PESQUISA EM FOCO

São Luís, v. 22, n. 2, Jul./Dez. 2017

\section{CONSIDERAÇÕES FINAIS}

Ao tomar como referência algumas das principais leis e documentos sobre o assunto abordado, ampliamos a compreensão sobre as contribuiç̧̃̃es de Paulo Freire para a educação de jovens e adultos, e observamos o processo histórico que norteou a EJA. Nesta pesquisa bibliográfica compreendemos que o processo de formação docente para a EJA, bem como suas conquistas e dificuldades, ainda se apresenta como desafiadores. Com o propósito de analisar a modalidade EJA no contexto das pesquisas sobre do PNE e contribuir para futuras reflexões acerca do protagonismo da EJA na formação de professores, verificamos a necessidade de refletir sobre as metas que tratam especificamente da EJA no Plano Nacional de Educação 2014-2024, e sua importância na efetivação das políticas públicas para uma educação gratuita e de qualidade.

Diante dos resultados das pesquisas consultadas sobre a EJA e as metas do PNE observamos a influência do cenário político no delineamento dos referenciais para a modalidade. Constatamos que no campo do discurso tem sido amplamente proclamada a necessidade de melhoria da qualidade do ensino ofertado aos jovens e adultos, porém, no campo prático, não são dadas as condições tanto formativas para os professores, quanto de investimento nesta área. Um dos desafios da modalidade tem sido o aspecto da permanência, ou seja, com a ênfase no aumento do número de matrículas em turmas de jovens e adultos, emerge também a preocupação em criar sistemas de monitoramento e acompanhamento do fluxo de alunos. A melhoria na qualidade do ensino em específico, na modalidade EJA, depende de uma série de ações que vão desde maior investimento nas estruturas das instituições que atendem este público até a revisão dos modelos de formação de professores que ainda pouco contempla a docência para jovens e adultos.

Percebemos ainda, a incoerência entre a necessidade de cumprimento das metas do PNE para a melhoria da qualidade da educação nacional, com a efetivação do veto do presidente, autorizando, o remanejamento de recursos destinados ao PNE 
passando para áreas consideradas prioritárias mediante a crise econômica. Considerando que o papel das políticas públicas é de organizar estratégias e delimitar recursos e esforços para o acompanhamento dos objetivos educacionais, configura-se contraditório comprometer a manutenção das metas do PNE em nome do ajuste fiscal.

No tocante à formação docente para a atuação na EJA, constatamos nos resultados de pesquisas sobre o tema (SILVA, 2014; VELOSO, 2014; FERRARI, 2015) que as instituições de ensino deveriam oferecer licenciatura específica para a EJA, ou destinar parte da carga horária de estágio curricular supervisionado para a docência nesta modalidade. Segundo Veloso (2014) os professores precisam ser capacitados para atender as demandas da modalidade de ensino, tanto no que se refere aos métodos, quanto na compreensão das especificidades próprias da modalidade. Assim, no contexto das metas do PNE relacionadas à EJA não há menção à revisão dos cursos de licenciatura para inclusão da EJA como cenário profissional docente ou à necessidade de discutir a identidade profissional do professor que atua na área.

Por fim, concluímos que a EJA continua sendo uma modalidade desprestigiada no cenário das políticas públicas, já que os resultados das pesquisas indicaram incongruências relacionadas à educação de jovens e adultos. O cenário educacional da modalidade evidencia carências que vão desde a concepção de ensino e aprendizagem de jovens e adultos como mera formalidade para obtenção de diploma até a caracterização da modalidade como opção profissional secundária.

\section{REFERÊNCIAS}

ALVARENGA, M. S. A educação de Jovens e Adultos no PNE 2014 - 2024: entre os ajustes econômicos e os direitos sociais na atual conjuntura de crises no Brasil. Revista Educação e Cultura Contemporânea. v.13, n. 33, p. 121-138, 2016.

BEISIEGEL, C. R. Paulo Freire. Recife, PE: Fundação Joaquim Nabuco/Editora Massangana, 2010.

BEZERRA, A. A. C.; MACHADO, Márcia A.C. Política de formação de formadores para a educação de jovens e adultos (EJA) no plano nacional de educação PNE 2014-2024.

Revista Brasileira de Pesquisa sobre Formação Docente. v.08, n. 14, p. 65-82. Editora Autêntica. Belo Horizonte, 2016. 
Pesquisa em Foco ISSN (2176-0136)

http://ppg.revistas.uema.br/index.php/PESQUISA EM FOCO

São Luís, v. 22, n. 2, Jul./Dez. 2017

BRASIL. Movimento Brasileiro de Alfabetização Assessoria de Organização e Métodos MOBRAL: sua origem e evolução. Rio de Janeiro, 1973. Disponível em:< https://goo.gl/c1N32P >. Acesso em: 24 de set. 2017.

BRASIL. Constituição da República Federativa do Brasil. Brasília, 1988. Disponível em:<http://www.planalto.gov.br/ccivil_03/constituicao/constituicao.htm>. Acesso em: 22 de ago. 2017.

BRASIL. Ministério de Educação e Cultura. LDB - Lei no 9394/96, de 20 de dezembro de 1996 estabelece as diretrizes e bases da Educação Nacional. Brasília. MEC. 1996.

Disponível em:<http://www.planalto.gov.br/ccivil_03/leis/19394.htm >. Acesso em 15 mai. 2017.

BRASIL. Plano Nacional de Educação - Lei n.10.172 de 09 de janeiro de 2001. Disponível em:<http://www.planalto.gov.br/ccivil_03/leis/leis_2001/l10172.htm >. Acesso em 22 ago. 2017.

BRASIL. Diretrizes Curriculares para a Educação de Jovens e Adultos. SEED/Curitiba, 2006. Disponível em:< https://goo.gl/yRrRr7 > Acesso em: 15 mai. 2017.

BRASIL. Paulo Freire: Patrono da Educação Brasileira. Lei n. 12.612 de 13 de abril de 2012. Disponível em:< https://goo.gl/s3n39i >. Acesso em 22 ago. 2017.

BRASIL. Plano Nacional de Educação - Lei n.13.005, de 25 de junho de 2014a. Disponível em:<http://www.planalto.gov.br/ccivil_03/_ato20112014/2014/lei/l13005.htm>. Acesso em 24 set. 2017.

BRASIL. Planejando a próxima década: Conhecendo as $\mathbf{2 0}$ metas do Plano Nacional de Educação. Ministério da Educação / Secretaria de Articulação com os Sistemas de Ensino (MEC/ SASE), 2014b. Disponível em:< https://goo.gl/dwT8D6 >. Acesso em 15 mai. 2017.

BRASIL. Instituto Nacional de Estudos e Pesquisas Educacionais Anísio Teixeira.

Relatório do 1o ciclo de monitoramento das metas do PNE: biênio 2014- 2016. Brasília: Inep, 2016. Disponível em:<https://goo.gl/QTEi69> Acesso em 20 set. 2017.

BRASIL. Lei de Diretrizes Orçamentárias - Lei n. 13.473, de 08 de agosto de 2017. Disponível em:< https://goo.gl/PNtauk >. Acesso em 24 set. 2017.

CORRÊA, A. L. Educação de massa e ação comunitária. Rio de Janeiro: Editora Mobral, 1979. 
CUNHA, L. A. Educação, estado e democracia no Brasil. São Paulo: Cortez, 1991.

DI PIERRO, M. C. A educação de jovens e adultos no Plano Nacional de Educação: Avaliação, desafios e perspectivas, Campinas, SP: v.31, n.112, p. 939-959, 2010.

FERRARI, S. M. Educação de Jovens e Adultos: a escolarização em questão. $115 f$ Dissertação (Mestrado em Educação). Centro Universitário Salesiano de SP. Americana, 2015.

FREIRE, P. A importância do ato de ler: em três artigos que se completam. 45. ed. São Paulo: Cortez, 2003.

FREIRE, P. Pedagogia da Autonomia. 36. ed. São Paulo: Paz e Terra. 2007.

FREIRE, P. Educação como prática de liberdade. 14. ed. Rio de Janeiro: Paz e Terra. 2011.

KOSSMANN, D. C.; BALADELI, A. P. D. Proposições sobre a educação progressista: diálogos com Paulo Freire. In: SIMPÓSIO NACIONAL DE EDUCAÇÃO, 3., SEMANA DE PEDAGOGIA, 23. Unioeste, Anais... Cascavel, 2012.

MARCONI, M. A.; LAKATOS, E. M. Fundamentos de Metodologia Científica. 5. ed. São Paulo: Atlas. 2003.

NOGUEIRA, P.H.Q.; MIRANDA, S.A. D. (orgs.). Educação de Jovens e Adultos: um campo de direitos e responsabilidade pública. In: NOGUEIRA, P. H. Q. et al. Miguel Gonzales Arroyo: Educador em diálogo com o nosso tempo. Belo Horizonte: Autêntica editora, 2011. p. 95-120.

PARANÁ. Secretaria de Estado da Educação Superintendência da Educação. Diretrizes Curriculares da Educação de Jovens e Adultos. Curitiba, PR: SEED, 2006.

PARANÁ. Secretaria de Estado de Educação. Educação Profissional integrada à Educação de Jovens e Adultos - PROEJA. Departamento de Educação Profissional. Curitiba, PR: SEED, 2010.

PELETTI, J.A. A Política Educacional para EJA - Educação de Jovens e Adultos: 0 CEEBJA - Centro Estadual de educação básica para jovens e adultos - Professora Joaquina Mattos Branco. 126f. Dissertação (Mestrado em Educação), Universidade Estadual do Oeste do Paraná, UNIOESTE, Cascavel, 2016.

ROMANELLI, O. O. História da educação no Brasil. 6. ed. Petrópolis: Vozes, 1978. 
Pesquisa em Foco ISSN (2176-0136)

http://ppg.revistas.uema.br/index.php/PESQUISA EM FOCO

São Luís, v. 22, n. 2, Jul./Dez. 2017

SAVIANI, D. Política e educação no Brasil: o papel do Congresso Nacional na Legislação do ensino. 2. ed. São Paulo: Cortez, 1988.

SILVA, J. B. Políticas educacionais da EJA e a formação do educador de jovens e adultos no município de Curitiba, de 1996 a 2012, à luz da visão da docência de Paulo Freire. 130f. Dissertação (Mestrado em Educação), Pontifícia Universidade Católica do Paraná, PUCPR, Curitiba, 2014.

VELOSO, Z. V. As Práticas pedagógicas na Educação de Jovens e Adultos (EJA): interfaces com as políticas e diretrizes curriculares. 120f. Dissertação (Mestrado em Educação), Pontifícia Universidade Católica de Goiás. PUC, Goiânia, 2014. 